\title{
Que as águas voltem a minar nas minas (dos) gerais: os cerrados pedem socorro!
}

\begin{abstract}
Resumo: Este trabalho objetiva analisar os impactos sociais e ambientais nos Cerrados do Alto Vale Jequitinhonha e do Norte de Minas Gerais, causados pelos projetos e empreendimentos capitalistas implantados a partir da segunda metade do século XX. A metodologia de pesquisa baseou-se em algumas referências bibliográficas e na abordagem qualitativa. A coleta dos dados foi realizada através do uso de formulários de entrevistas semiestruturadas e com o auxílio da gravação e transcrição de fontes orais para obter-se uma maior riqueza de informações. Constata-se nas comunidades rurais estudadas que o principal problema ambiental ocorrido nos cerrados impacta diretamente a disponibilidade de água para as populações sertanejas. 0 grande vilão tem sido as monoculturas de eucalipto que, segundo os camponeses, reduziu drasticamente a água em Minas Novas. Já no Norte de Minas, especialmente em Campo Azul, o carvoejamento de mata nativa para alimentar as siderúrgicas mineiras tem literalmente consumido os cerrados e, junto com eles, suas gentes e suas culturas.
\end{abstract}

\section{May the water returns in the mines of minas gerais: the savannas ask for help}

\footnotetext{
Abstract: This article intends to analyze social and environmental impacts in the savannas of upper Vale Jequitinhonha and northern Minas Gerais, caused by the capitalist enterprises and projects implemented from the second half of the twentieth century. The research methodology was based on some references and qualitative approach. Data collection was performed through the use of interview forms and semi-structured with the aid of the recording and transcription of oral sources to obtain a greater wealth of information. It was found in rural communities studied that the main environmental problem occurred in the savannah directly impacts the availability of water for the region's people. The biggest embarrassment has been monoculture eucalyptus, according to the farmers, drastically reduced the water in Minas Novas. In the North of Minas, especially in Campo Azul, the charcoal from native forests to feed the steel companies of Minas Gerais has literally consumed the savannahs and, along with them, their people and their cultures.
}

Marcos Nicolau Santos da Silva *
* Mestre em Geografia pela Universidade Federal de Minas Gerais (UFMG).

\section{Palavras-chave: \\ Cerrados; Impactos ambientais; Norte de Minas Gerais; Vale do Jequitinhonha.}

\section{Key-words:}

Savannas; environmental impacts; North of Minas Gerais; Jequitinhonha Valley. 


\section{Introdução}

"Assim é que ao se entrar no início do século XXI, encontra-se em suspenso o destino do cerrado. Se as próximas décadas trarão sua ruína ou salvação, ainda não se pode dizer".

Altair Sales Barbosa.

Os cerrados brasileiros, em todas as regiões de abrangência, estão agonizando. Junto com eles, suas diversas populações também pedem socorro. Talvez não seja novidade, mas vale lembrar que é o segundo maior ecossistema brasileiro em extensão e considerado como a maior savana tropical do mundo em área contínua de um único país (ALMEIDA, 2005).

$\mathrm{O}(\mathrm{s})$ cerrado(s) ocupa $(\mathrm{m})$ uma área de aproximadamente $2.000 .000 \mathrm{~km}^{2}$, o que representa $23 \%$ do território brasileiro (ALMEIDA Jr., 1994) e só em Minas Gerais sua área de ocorrência compreende 30,8 milhões de hectares, correspondente a 53\% território mineiro (RIBEIRO, 2000).

Ab'Sáber (2003) ressalta que a vegetação dos cerrados, apesar de conviver com alguns dos piores solos do Brasil, conseguiu a façanha ecológica de resistir às queimadas, renascendo das próprias cinzas, como uma espécie de fênix dos ecossistemas brasileiros. Entretanto, essa vegetação não resiste aos violentos artifícios tecnológicos inventados pelos homens ditos civilizados.

O título deste texto já nos mostra o maior problema enfrentado pelas populações sertanejas - a escassez de água. Todas as modificações mais significativas ocorridas, sobretudo nos últimos 50 anos, nos diversos ambientes dos cerrados impactam direta ou indiretamente a disponibilidade de água. Nesse sentido, vamos abordar os principais impactos ambientais e sociais destacados em nossa pesquisa em áreas dos cerrados do Norte de Minas e do Vale do Jequitinhonha.

As áreas de estudo contempladas pela pesquisa são as seguintes comunidades rurais: Cachoeira do Fanado e Cachoeira da Lagoa, em Minas Novas, no Vale do Jequitinhonha; Cabeceiras do Mangaí, em Japonvar, e mais cinco localidades rurais do município de Campo Azul, no Norte de Minas Gerais. A pesquisa realizou-se a partir de 15 entrevistas semiestruturadas que foram feitas com as famílias camponesas em cada município, totalizando 45 entrevistas. A escolha das áreas de estudo em três municípios diferentes deu-se em função de serem localidades as quais apresentam número significativo de famílias camponesas e que também vivem da economia extrativista do pequi.

Para este artigo, procuramos usar somente a abordagem de pesquisa qualitativa, privilegiando os resultados da observação direta e da percepção dos camponeses que obtivemos através dos relatos orais, gravados e/ou registrados no diário de campo. Cabe salientar que os relatos orais transcritos foram mantidos na linguagem coloquial, fazendo-se o mínimo de correções, com o objetivo de manter a originalidade sem, portanto, ter a intenção de ridicularizar os sujeitos da pesquisa. Por conseguinte, não revelamos a identificação dos camponeses entrevistados, apenas destacamos o sexo, a idade e a localidade de residência dos mesmos.

A opção por enfatizar os relatos orais também é uma forma encontrada para darmos voz a quem não deixaria testemunho. Com isso, resgatamos o passado dos homens e dos lugares, as disputas pelo território e, principalmente, os impactos aos ambientes dos cerrados e à sua gente.

Abordamos inicialmente, à luz do referencial teórico, o processo de modernização do sertão mineiro. Em seguida, apresentamos os impactos sociais e ambientais decorrentes desse processo para as comunidades rurais camponesas estudadas no Norte de Minas Gerais e no Vale do Jequitinhonha. Por último, fizemos algumas considerações finais de cunho crítico e reflexivo, levando em conta a situação atual dos Cerrados e suas perspectivas para o campesinato sertanejo.

\footnotetext{
Que as águas voltem a minar nas minas (dos) gerais: os cerrados pedem socorro! 


\section{A modernização dolorosa dos cerrados}

A ocupação do sertão mineiro data de aproximadamente 12 mil anos desde a entrada dos primeiros grupos humanos. Durante a colonização, os bandeirantes aprenderam com os indígenas a sobreviver da caça, da coleta vegetal, da pesca e da agricultura nômade nos Cerrados. Os colonizadores e seus escravos africanos introduziram a mineração e a pecuária, as quais produziram transformações significativas na paisagem. A sociedade constituída ao longo do século XVIII no Sertão Mineiro é marcada pela rebeldia de potentados, quilombolas, garimpeiros e índios, que se utilizavam dos Cerrados para fugir das perseguições das autoridades coloniais. No século XIX, o Sertão Mineiro foi caracterizado pelo "interesse da Ciência, que propunha melhorias na sua economia e a introdução da indústria, da navegação a vapor e das ferrovias, que foram modificando significativamente o Cerrado e a vida de sua gente" (RIBEIRO, 2006, p. 13).

Ainda nesse contexto do século XIX até a segunda metade do século XX, as modificações nos Cerrados do Norte de Minas Gerais ocorreram, segundo Rodrigues (2000), mais voltadas à expansão das atividades produtivas destinadas ao mercado interno, motivadas pela solicitação de novos produtos pelo mercado internacional - 0 algodão e o couro -, melhoria das vias de escoamento da produção e o crescimento demográfico. Consoante Brito (2006), o século XX foi assinalado pela chegada da ferrovia e a abertura das rodovias, impulsionando as transformações em curso, provocando naturalmente a diminuição das distâncias, o aumento da mobilidade populacional e a abertura das novas possibilidades de comércio.

Fundamentando-se em Ribeiro (2000), Agostinho de Jesus (2007) salienta que a expansão econômica do Vale do Jequitinhonha, entre os séculos XIX e XX, ocorreu de forma muito lenta, prejudicada pela sua posição geográfica - Nordeste de Minas Gerais. Pelas suas características, fora confundido como Norte, Nordeste e Leste mineiros. De acordo com o autor, quando associado ao Leste, o Nordeste se confundia como uma vasta fronteira. Quando confundido com o Norte, era considerado uma área de pecuária atrasada e de pouca expressão econômica, e, na maioria das vezes, como uma região estagnada e desqualificada, do ponto de vista da modernidade da época.

Mazzetto Silva (2009), concentrando-se mais na análise sobre a modernização dos Cerrados no século XX, divide a ocupação predatória em três momentos: a construção de Brasília na década de 1960, a implantação dos programas estatais modernizantes a partir da década de 1970 baseados na Revolução Verde - e o período atual, da globalização neoliberal, de expansão do agronegócio em redes nacional e internacional. Conforme o autor, até o ano de 1960 havia nos Cerrados cerca de 11 milhões de habitantes, dos quais 7 milhões estavam nas zonas rurais, mas até aquele ano, as regiões não tinham sofrido fortes agressões.

\footnotetext{
A lógica tradicional de ocupação dos Cerrados, baseada na criação de gado, extrativismo, caça, pesca e agricultura de subsistência não rompeu os processos ecológicos que mantinham o funcionamento dos mais de dez ecossistemas que se abrigam dentro do domínio do Cerrado (MAZZETTO SILVA, 2009, p. 62).
}

Nesse mesmo contexto, Oliveira (2008) afirma que foi o caráter industrial da agricultura capitalista do país a mola propulsora da produção em grande escala das culturas de grãos, cuja obtenção de preços altos no mercado garantia lucro certo nesses empreendimentos. "O Estado atuou no sentido de estimular esses setores competitivos, deixando praticamente abandonadas as culturas que se têm constituído, historicamente, na alimentação básica dos trabalhadores brasileiros" (OLIVEIRA, 2008, p. 516).

0 autor cita algumas políticas públicas voltadas à implementação desses novos polos de desenvolvimento: o Polocentro, destinado à expansão da cultura de grãos - soja e arroz principalmente - no cerrado do Brasil Central; o Polonordeste, responsável pelos investimentos na Zona da Mata nordestina e no Sertão. Neste último, foram privilegiados os projetos de irrigação, especialmente na área do rio São Francisco; e o Poloamazônia, com investimentos em exploração

Geografia Ensino \& Pesquisa, v. 16, n.3 p. 93-106 set./dez. 2012

Silva, M. N. S.

ISSN 2236-4994 I 95 
agromineral e agropecuária na região amazônica. Para Oliveira (2008, p. 516), "dessa política derivaram os atuais processos de desmatamento e de violência na região [amazônica]".

Acrescentamos, ainda, que esses mesmos processos ocorreram também nas áreas de caatinga e cerrado, oriundos dessas políticas de polos de desenvolvimento, além dos incentivos internos no sertão mineiro, no caso do governo de Minas Gerais. Segundo Mazzetto Silva (2009), foram desenvolvidos os programas: Programa de Crédito Integrado e Incorporado dos Cerrados PCI (1972); Programa de Assentamento Dirigido do Alto Paranaíba - PADAP (1973); Programa de Desenvolvimento dos Cerrados - POLOCENTRO (1975); Programa de Cooperação Nipo-Brasileira de Desenvolvimento dos Cerrados - PRODECER I, II e III (1979, 1985, 1994, respectivamente), dentre os quais, apenas o PRODECER III não foi implantado no estado de Minas Gerais.

A propósito, Brito (2006) acrescenta os programas Planonoroeste II e o MG-II, os quais também contemplaram o Norte de Minas Gerais.

Desse quadro de arranjo político e econômico que começou a emergir a partir da década de 1960, principalmente pelo impulso dado após a criação da Superintendência de Desenvolvimento do Nordeste - SUDENE em 1959, somado ao apoio da Companhia de Desenvolvimento dos Vales do São Francisco e Parnaíba - CODEVASF, o Norte de Minas Gerais passa por profunda transformação, como nunca havia experimentado. Nesse contexto, também se concentram os principais impactos sociais, econômicos e ambientais na região, resultados das externalidades negativas e mal planejadas, as quais, durante muito tempo, serviram e ainda servem de crítica ao modelo desenvolvimentista, autoritário, arbitrário e contraditório das políticas públicas no país.

Ao analisar a política de desenvolvimento destinada ao cerrado mineiro a partir desse período, Rodrigues (2000, p. 123) destaca: "o Estado centrou seus incentivos em quatro eixos principais para induzir o crescimento econômico no Norte de Minas: (a) grandes projetos agropecuários; (b) industrialização; (c) reflorestamento; (d) projetos de irrigação". Entre eles, podemos destacar o projeto de fruticultura irrigada de Pirapora; o Projeto Jaíba; a implantação de indústrias com incentivos fiscais, sobretudo nas cidades de Montes Claros, Bocaiúva, Pirapora e Várzea da Palma. Entretanto, a grande maioria encerrou suas atividades na região após o fim da isenção de impostos, resultando numa urbanização precária, com elevada taxa de desemprego, e na substituição das áreas de cerrados por monoculturas de eucalipto, causando, sem dúvida, um dos maiores impactos sociais e ambientais da região.

O Vale do Jequitinhonha, por sua vez, ficou excluído dos incentivos da SUDENE. Assim, diferente do Norte de Minas Gerais, o Vale do Jequitinhonha não absorveu as indústrias, entretanto, foi parcialmente favorecido com a expansão delas em outras regiões. Entre outras transformações sofridas por esta região, destacamos, por exemplo, conforme afirma Agostinho de Jesus (2007), que o Vale passou por transformações significativas associadas ao desenvolvimento capitalista a partir de 1950, integrando-se cada vez mais a um mercado ampliado pela industrialização de outras regiões e pela abertura e melhoria das condições de transporte. "Esse processo facilitou o acesso de produtos regionais, especialmente o gado, a mercados mais distantes, e possibilitou a entrada, nos mercados do Jequitinhonha, de produtos agrícolas, que concorriam com a produção local" (AGOSTINHO de JESUS, 2007, p. 22).

Depois desse período, o Vale do Jequitinhonha sofreu várias oscilações na sua dinâmica interna de produção e de trabalho, ora beneficiado pela modernização da agricultura e da industrialização em outras regiões, ora prejudicado pelas mesmas. De acordo com Ribeiro (1993), citado por Agostinho de Jesus (2007), ocorreu um processo de expropriação camponesa na região, culminando com o agravamento do quadro de dificuldades da produção camponesa - fato este justificado pela implantação de projetos agrícolas e de reflorestamento, principalmente a cafeicultura, com incentivos do Estado, aumentando, portanto, as pressões sobre a terra. Vários diagnósticos estaduais e nacionais identificaram o Vale do Jequitinhonha como uma das regiões mais pobres do país, sendo destacada como "área problema", "bolsão da pobreza" etc. É uma região de "estagnação secular", motivos pelos quais se justificava a necessidade de "grandes projetos", a fim de alcançar o resgate do Vale. 
Analisando-se particularmente o caso de Minas Novas, onde se situa uma de nossas áreas de estudo, Agostinho de Jesus (2007) destaca que o reflorestamento com eucalipto objetivava atender ao Segundo Programa Nacional de Desenvolvimento - II PND, para fomentar o crescimento da siderurgia e das indústrias de celulose e papel. A cafeicultura moderna implantada na região teve o incentivo do Instituto Brasileiro do Café - IBC e foi liderada por fazendeiros da região e empresários do Sul de Minas, Paraná e São Paulo, atraídos e beneficiados pelos baixos preços das terras e da mão de obra. Todavia, enquanto o café concentrou-se mais no município de Capelinha, apenas uma parte dele abrangeu Minas Novas; já o eucalipto se difundiu pela maior parte do Vale, especialmente nas áreas do Alto e Médio Jequitinhonha. Além desses projetos, também tiveram importância significativa as barragens para irrigação e energia, a melhoria de estradas, da comunicação e incentivos à exploração mineral.

Se, por um lado, o Vale integrou-se ao mercado nacional, sobretudo através do reflorestamento e da cafeicultura, por outro lado, as consequências para a população foram enormes. Surgiram conflitos fundiários entre fazendeiros, empresas e camponeses devido à limitação do acesso à terra; modificação da estrutura agrária na região, com a proliferação de estabelecimentos rurais acima de 100 hectares, excetuando-se as grotas, que são os territórios onde se confinou principalmente a população camponesa ao longo dos vales e cursos d'água; grilagem de terras, muitas vezes por meio de documentos falsos; e apropriação das terras consideradas devolutas pela ausência de documentação de propriedade, cujos contratos de exploração foram concedidos às empresas pelo Estado por mais de vinte anos (AGOSTINHO DE JESUS, 2007).

\section{Os descaminhos dos cerrados: entre o Vale do Jequitinhonha e o norte de Minas}

Figura 1 - Comunidade rural Cachoeira da Lagoa, em Minas Novas, margeada pelo eucaliptal da empresa ArcelorMittal.

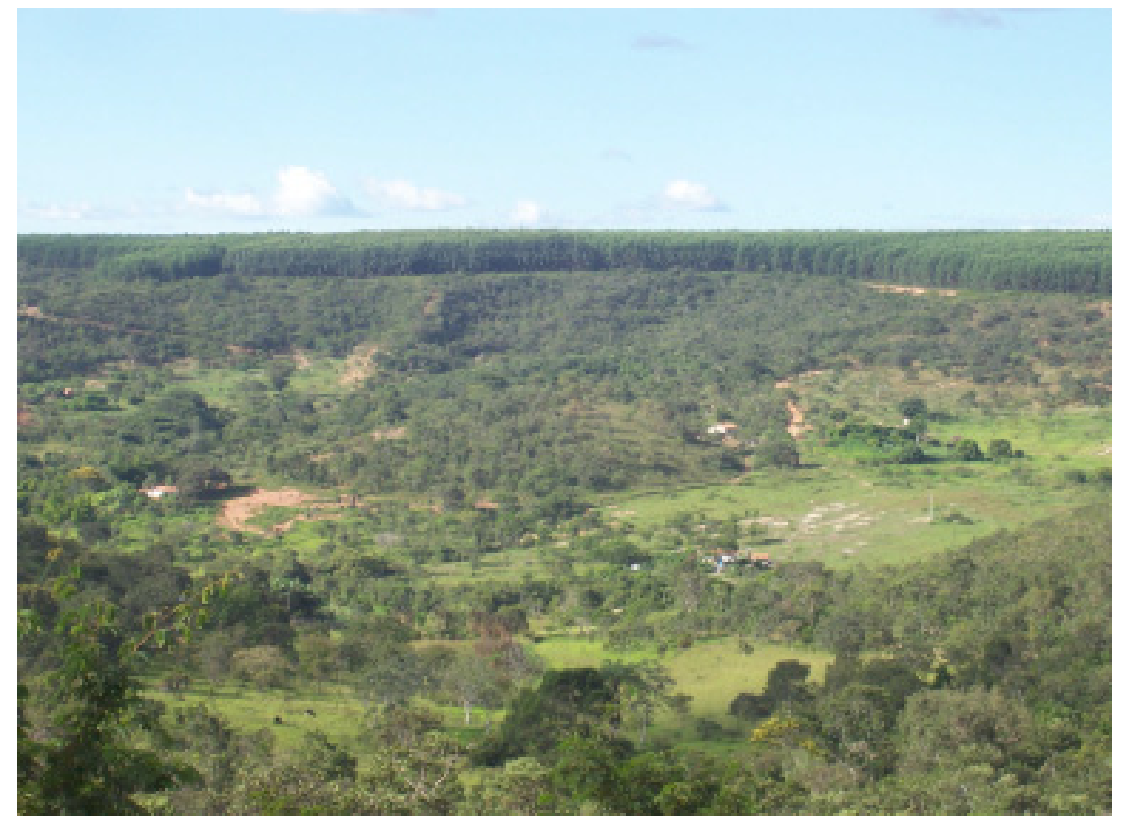

Fonte: SILVA, M. N. S.; Pesquisa de campo, abril de 2010.

A Figura 1 ilustra uma parte do território rural Cachoeira da Lagoa, no município de Minas Novas, margeada pelo eucaliptal da empresa ArcelorMittal, antiga Acesita. Esse é um exemplo emblemático de comunidades rurais confinadas nas grotas, conhecido também como território de confinamento, pois a monocultura do eucalipto cobriu toda a chapada, chegando até a descida do terreno, onde não era mais possível a entrada das máquinas.

Geografia Ensino \& Pesquisa, v. 16, n.3 p. 93-106 set./dez. 2012

Silva, M. N. S. 
Segundo as famílias camponesas entrevistadas nesta comunidade, a empresa somente respeitou os limites das propriedades até então cercadas, as outras áreas foram todas incorporadas à monocultura, chegando a ponto de muitas famílias limitantes terem perdido suas partes de terras na chapada. No caso da comunidade rural vizinha, Cachoeira do Fanado, oposta à Cachoeira da Lagoa, o problema foi menor, pelo fato de não ser diretamente confrontante com o eucaliptal, embora seja através deste 0 seu acesso.

Os camponeses sertanejos dessas comunidades rurais perderam a maior parte de seu território para a monocultura do eucalipto. Eles não vivem mais o território na sua totalidade; do território total concebido pelos camponeses, ficaram apenas lembranças guardadas na memória e, nesta, pelo menos para os mais velhos, que tiveram a experiência total do território, não há como apagar. Os mais novos, por exemplo, não conheceram outro território, além da visão desigual e desleal mostrada pelas diferenças de poder entre a produção do território camponês ao lado da produção do território capitalista.

O território camponês eram as grotas, onde as famílias moravam, plantavam suas roças e criavam os pequenos animais, e mais a chapada, de onde retiravam a madeira, a lenha, aproveitavam os frutos nativos para alimentação, criavam o gado, etc.

"Nós trabalhava era nas grotas, de jeito que nós esqueceu as chapadas pra lá, aí a Acesita chegou e tomou conta" (Camponês, 63 anos, Cachoeira do Fanado). A fala deste camponês caracteriza a divisão simbólica do território camponês, dividido entre a grota, espaço de moradia e terra de trabalho, e a chapada, a qual complementava a vida camponesa através do fornecimento de madeira, de frutos, ervas e de pastagem natural para as criações. De acordo com Guerrero (2009, p. 85), o complexo grota-chapada "permite duas formas de apropriação da terra: uma que se caracteriza pela apropriação privada das terras baixas (veredas e grotas), e a outra, pela apropriação comum das terras altas (as chapadas)", de modo que a chapada funciona como complemento à lavoura de subsistência (RIOS-NETO e VIEIRA, 1989 apud GUERREIRO, 2009, p. 85). A autora ainda completa que as chapadas têm o papel de reabastecer os lençóis freáticos da região, seriamente comprometidos após o plantio de eucalipto.

As palavras do mesmo camponês na sequência reforçam nossa explicação. Segundo ele, no início não se usava a chapada, mas, depois, sua história contada termina por ratificar o seu uso, mesmo não sendo o uso tradicional - o plantio e o cuidado com a lavoura. Além disso, destaca 0 impacto causado à biodiversidade existente no cerrado que cobria a chapada:

Uai, não usava nada não, porque lá era só madeira, carrasco e tinha tudo quanto é fruta também, bicho... Tinha bicho demais, tudo quanto é tipo de bicho, tatu... aí eles começou a destruir... até os canarinhos, aqui tinha canarinho que vou falar com cê, dava dó... Depois que eles começou a desmatar esse "trem" aí, até os bicho acabou nesse "trem" aí, acho que o veneno foi comendo, porque eles punham muito veneno na terra, aí os bichinhos comeu e morreu tudo. (...) Tinha um velho meritão aqui em Ribeirão do Santo, ele tinha criação de gado, de égua, de porco. Pra eles tirar... quando nascia um porco, o porco ficava aí [solto na chapada] dois anos, sem cortar nem a clina, pra pegar tinha que arrumar um... Papai tinha um cachorro pra poder pegar, na chapada. 0 bicho era brabo, quando batia um laço num bezerro ou numa égua, o bicho gritava mesmo. Era grande, aí eles fez o curral aqui na Cachoeira, aí eles vinha e ia lá na chapada e buscava esse trem [o porco] pra poder cortar a clina, carimbar, aí tornava soltar de novo

Geografia Ensino \& Pesquisa, v. 16, n. 3 p. $93-106$ set./dez. 2012

Que as águas voltem a minar nas minas (dos) gerais: os cerrados pedem socorro! e ele ia embora pra chapada. Era uma beleza moço, e não morria também não, só se onça não comia lá.

O próprio desfecho de buscar a criação na chapada, cuidar e soltá-la novamente demonstra a relação dos camponeses com o seu território aberto, o qual, além de ser aberto, ainda era compartilhado. A ideia de carimbar [ou ferrar] a criação aponta para a identificação do direito de 
propriedade sobre 0 animal, solto no território comum. Isso corrobora com a análise de Ribeiro e Galizoni (2007, p. 117), os quais afirmam que os campos foram utilizados para criação por várias décadas. Consoante os autores, os sítios, cujos terrenos eram mais férteis, estavam localizados nas partes mais baixas do relevo, enquanto os campos eram usados em comum para uma pecuária de soltas. Costumeiramente, "às vezes o gado era reunido, as crias eram ferradas e, novamente solto, o gado se alongava nos campos sem fim" (grifo dos autores).

Esses camponeses ficaram com as grotas e com a contabilidade de prejuízos, conforme relatado por um entrevistado:

Essas chapadas aí foi assim. Essas chapadas aí era tudo aberto. Era dono dela quem tinha um terreno até sair lá, até topar com ela lá e era tudo aberto. Não tinha cerca não, porque, de primeiro, ninguém fechava, ninguém tinha manga não. Esse terreno meu topa lá, na chapada. Mas, o seguinte foi esse. Na época teve uns cara meio esperto aí e fechou uns pedaço aí, mas a Acesita não deixou. Ela chegou e meteu foice, picada e foi fazendo picada, mas teve uma vez que um velho vendeu, e foi poucos, eu sei mesmo que um tio meu vendeu, irmão da minha mãe, vendeu um pedaço de chapada aí, lá em cima. Lá embaixo, um tal de Bastião Eduardo vendeu também. Vendeu pra um homem e o homem pegou e vendeu pra Acesita. Mas atrás deles teve muitos que ninguém vendeu, foi só algum que vendeu. $E$ ela embargou tudo, tomou conta de tudo. Agora mesmo eles tá pelejando pra o pessoal assinar pra ela, e ninguém quis assinar, os extremantes. Assinar pra poder ela... pra poder ficar sendo tudo dela, pra ela legalizar o "trem" pra ela, porque ela não tem documento de tudo. Ninguém quis assinar. Essas terras é do povo, a Acesita não comprou isso tudo não. Ela foi invadindo e tomou tudo. E o pior que a Acesita fez foi que acabou com a água. Acabou com a água de todo mundo, porque muita gente que morava aqui na roça tá morando na cidade por causa d'água. Tem gente que..., eu não, graças a Deus, mas já teve um vizinho aqui que levantou de manhã cedo e não tinha água pra fazer o café. $E$ antes de ela entrar para aqui esse ribeirão era um barulhão d'água, a mina dele era a Lagoa Grande. Plantou eucalipto quase dentro da lagoa e acabou com a lagoa, secou tudo. O eucalipto é assim..., todo dia eles tão falando[...], a televisão tá passando todo dia, que o eucalipto acaba com a água. Ele não solta a água, só chupa a água, e a madeira nativa ela puxa a água seis meses e corta a água seis meses. E tem um tempo aí que você corta qualquer pau e a água tá escorrendo, você pode encher vasilha. E o eucalipto, você corta ele pra ver se ele mina água? Não mina. Enquanto ele tá achando umidade pra ele chupar ele tá bonito, a hora que a umidade da água acabou aí agora ele seca e morre (Camponês, 63 anos, Cachoeira da Lagoa).

A fala do camponês acima é muito elucidativa, pois o mesmo mostra a questão da terra antes da chegada da empresa monocultora, a Acesita, hoje ArcelorMittal. O camponês mostra exatamente aquilo chamado por nós de território aberto do campesinato sertanejo, que foi reterritorializado pela lógica capitalista, sob a tutela do Estado.

Segundo os moradores que limitam com o eucaliptal, representantes da ArcelorMittal visitaram suas propriedades buscando recolher assinaturas dizendo que a empresa queria legalizar suas terras e que, para isso, precisava da anuência de cada proprietário. De fato, o registro da propriedade rural atualmente necessita de assinatura e concordância dos vizinhos, porém, neste caso, os camponeses se recusaram a assinar, principalmente porque desconheciam o conteúdo do documento e as verdadeiras intenções da empresa. Ademais, muitas famílias extremantes não concordam com a área ocupada pela empresa, pois alegam que tiveram partes de suas terras das chapadas "griladas" pela ArcelorMittal.

É interessante esse fato, sobretudo porque os camponeses já sabiam que a empresa havia tentado realizar o mesmo procedimento na comunidade rural de Capivari e não teria obtido êxito.

Geografia Ensino \& Pesquisa, v. 16, n.3 p. 93-106 set./dez. 2012
Silva, M. N. S.

ISSN 2236-4994 
Assim, todos já estavam "armados" para quando os representantes da empresa chegassem a suas comunidades. A notícia através do "boca a boca" chegou até Cachoeira do Fanado e Cachoeira da Lagoa antes mesmo da empresa.

A percepção do camponês, associada aos conhecimentos adquiridos a partir dos meios de comunicação sobre o maior consumo de água pelo eucalipto em relação à vegetação nativa da chapada, reflete os saberes do mesmo. Aqui não vamos entrar nas questões biológicas de absorção de água do eucalipto, por nosso trabalho contemplar, na realidade, os saberes tradicionais dos camponeses. Para nós, o importante é destacar o que foi aprendido, apreendido e vivenciado com a percepção dos camponeses. Todos os camponeses entrevistados apontam ser a monocultura a redutora, de forma drástica, da água da região. A fala de outra camponesa reforça a percepção da problemática: "No tempo da seca, as outras plantas ficam secas e o eucalipto não fica; ele fica sempre verde porque ele puxa a água de baixo da terra" (Camponesa, 50 anos, Cachoeira do Fanado).

A maior consequência para os camponeses é, sem dúvida, a eliminação dos recursos hídricos do município e de seus territórios de vida. A água para o camponês é o princípio da vida, pois a terra não produz sem água, a família não pode viver sem ela, nem os animais. 0 mesmo camponês mostra o passado e o presente da água na região:

\begin{abstract}
A água aqui não faltava não. Tudo quanto é córrego que você andasse aqui tinha água correndo, corria o ano todo e não secava. Nós bebia água era do córrego, panhava lá no ribeirão lá as vasilhas d'água e trazia pra dentro de casa, lavava roupa lá, tomava banho lá. Tinha água pra todo canto que o senhor andasse aqui, tinha água. Essas cabeceiras da Pindaíba aí tinha água pra todo canto. Hoje, você pode olhar aí, que água de Pindaíba de cabeceira só existe em dois lugares: nesse lugar onde que o menino comprou lá, e lá onde que minha mulher nasceu, que tem essas duas nascentes. Você pode andar desde lá da Bem Posta até sair em Minas Novas que essas cabeceiras tudo nada tem água. Então, os Capão aí não tem água e em muitos lugares eles roçaram os capão tudo e acabou (Camponês, 63 anos, Cachoeira da Lagoa).
\end{abstract}

Quando confrontamos a imagem da Lagoa Grande (FIG. 2) com a fala do camponês acima, e tantas outras lembranças de várias famílias mais antigas que conheceram o antes e o depois do eucalipto na região, associando aos córregos secos e às dificuldades atuais de acesso à água, vemos o quão grande foi o impacto da monocultura. É uma realidade muito angustiante para quem ouviu as histórias da fartura de água do passado e vê, hoje, a tristeza de muitas famílias vivendo sob medidas mitigadoras: as caixas de captação de água de chuva e o fornecimento de água através de caminhão pipa. Durante a entrevista, uma camponesa de 50 anos lembrou o seu tempo de infância, em que a mãe serviu a ela e aos irmãos, no almoço, pequi sem sal antes de irem para a escola, pois não havia possibilidade de ir até a cidade comprar o tempero devido à chuva. Segundo a camponesa, nessa época, choveu cinco meses seguidos e não havia transporte até a cidade. 
Figura 2 - Lagoa Grande situada na Vila de mesmo nome.

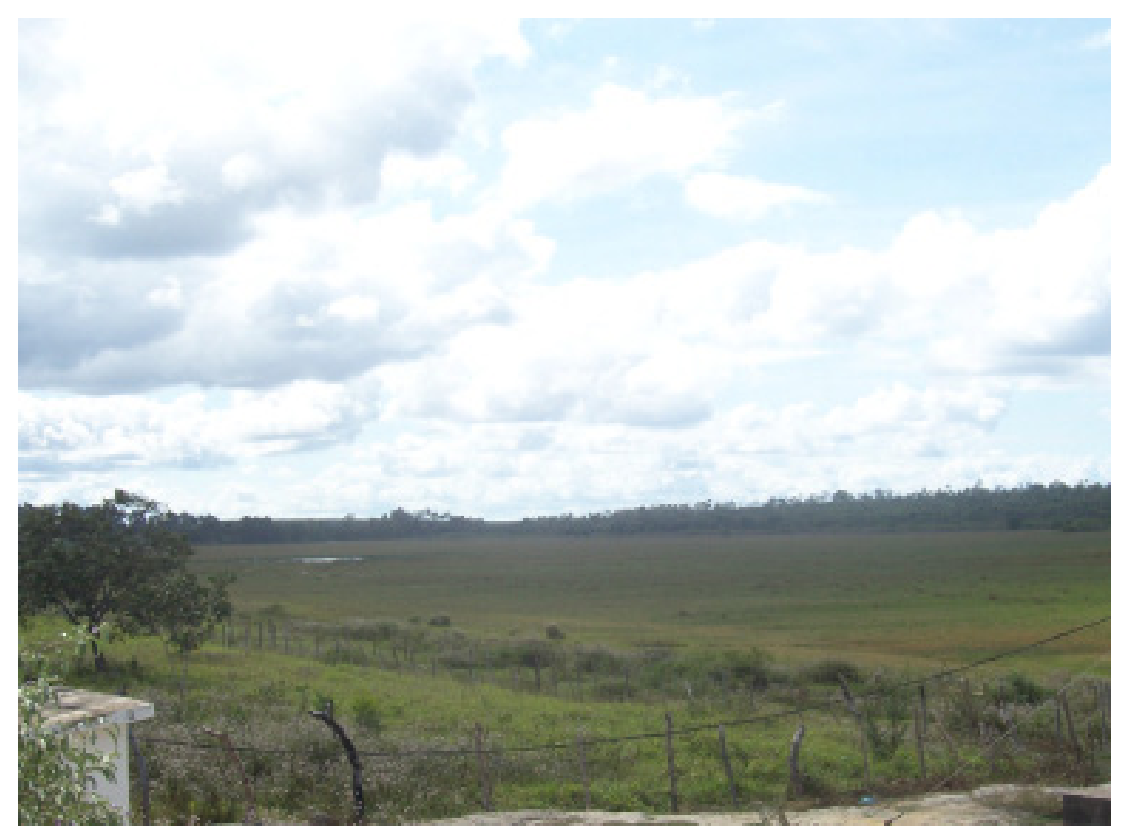

Fonte: SILVA, M. N. S.; Pesquisa de campo, abril de 2010.

A ilustração revela a famosa Lagoa Grande, a que vários camponeses fizeram referência durante as entrevistas e, hoje, encontra-se totalmente seca. 0 pequeno espelho d'água no centro da lagoa indica a recente passagem das últimas chuvas, ainda no mês de abril. A lagoa não enche mais, mesmo no período da chuva. Se observarmos as margens da lagoa seca ao fundo da figura, as copas das árvores de maior porte ainda são os eucaliptos abandonados pela ArcelorMittal. Atualmente, não se planta eucalipto na margem da lagoa. Nesta área, há somente um poço artesiano, feito para abastecer de água a vila Lagoa Grande.

Após a Lagoa Grande secar, a água como recurso comum e primordial se tornou um grande problema na manutenção dos camponeses. Tal fato, conforme já foi relatado, contribuiu até na emigração interna de famílias rurais para a cidade. Os relatos dos camponeses indicam que a água da lagoa secou definitivamente no início da década de 1990 e, consequentemente, os cursos d'água também secaram. "O Ribeirão da Cachoeira secou de 1994 pra cá; ele corria água 0 ano todo" (Camponesa, 34 anos, Cachoeira do Fanado). Atualmente, os córregos dos territórios rurais estudados permanecem secos durante a maior parte do ano, uma vez que só existe água correndo no período de chuva e pouco tempo depois.

Podemos estabelecer a chegada da ArcelorMittal na região a partir do ano de 1975, foi este o período mais citado pelos camponeses. Apesar de todos os impactos causados no início, os camponeses só os vivenciaram anos mais tarde. A própria história transcrita acima já fala por si só. Houve uma euforia pela possibilidade de emprego com carteira assinada, porque a instalação da monocultura exigiu grande número de mão de obra no início de suas operações. Quase todas as famílias destacaram, durante as entrevistas, que algum familiar já havia trabalhado na empresa. Atualmente, há trabalhadores na monocultura em apenas três das famílias entrevistadas.

Isso porque a ArcelorMittal (na época a empresa ainda se chamava Acesita) reduziu consideravelmente seu quadro de funcionários, primeiro, porque houve a mecanização da monocultura acompanhando o mesmo ritmo da agricultura moderna; e segundo, justificado pela paralisação das atividades entre o final da década de 1990 e início da década seguinte por imposição do município.

Um problema que está ocorrendo em Cachoeira do Fanado e Cachoeira da Lagoa é a expansão da atividade carvoeira entre os próprios camponeses, sobretudo os médios proprietários

Geografia Ensino \& Pesquisa, v. 16, n.3 p. 93-106 set./dez. 2012

Silva, M. N. S. 
de terras que começaram a plantar eucalipto nas grotas. No entanto, são poucos os camponeses que se dedicam a tal atividade nas comunidades estudadas, pois a maioria das famílias moradoras dispõe de pequena quantidade de terra. 0 que ocorreu foi que esses médios proprietários foram comprando pequenas parcelas de terras nas comunidades e começaram a investir na plantação de eucalipto.

O plantio de eucalipto nas grotas pelos médios proprietários de terras se torna contraditório à medida que se realizam tímidas ações ambientais para a recuperação dos recursos hídricos dos territórios estudados, por exemplo: a criação de pequenas bacias de contenção, barraginhas, proteção das matas ciliares das cabeceiras e pequenos córregos locais etc.

De maneira ilegal, o carvoejamento encontra-se entre as principais fontes de renda nos territórios da pesquisa, ocorrendo através dos recentes plantios de eucalipto nas propriedades camponesas. Além disso, quando a ArcelorMittal efetua o corte de uma área da plantação ela deixa as "sobras" da madeira no próprio local. Essas sobras são coletadas e utilizadas pelos pequenos produtores para a produção de carvão, o que é permitido pela empresa. Porém, obtivemos informação de que esses mesmos sujeitos coletam as madeiras inteiras, ação proibida pela empresa. A atuação dos pequenos produtores de carvão ocorre geralmente no período noturno, momento no qual a fiscalização da empresa é insuficiente. Também é nesse período que a madeira é transformada em carvão. Por exemplo, um de nossos entrevistados, durante o dia, trabalha na roça e na criação dos animais; já à noite, o mesmo camponês trabalha como motorista fazendo o transporte da madeira do eucaliptal para a propriedade na comunidade rural onde será feita a queima.

É necessário colocar que a madeira queimada em Cachoeira do Fanado e Cachoeira da Lagoa não é destinada apenas à produção de carvão. Muitas famílias camponesas também fazem a coleta das "sobras" de madeira do eucaliptal da ArcelorMittal para utilizar como lenha no uso doméstico. A própria empresa permite essa coleta sob a condição de ser apenas de uso doméstico.

O impacto do carvoejamento ilegal não é exclusividade apenas dos territórios de Minas Novas. Em Campo Azul, no Norte de Minas Gerais, essa prática também é bastante generalizada. Enquanto na primeira localidade, o carvão é feito de matéria-prima de reflorestamento de eucalipto, na segunda é exclusivamente oriunda de mata nativa do cerrado. Tal prática, conforme os relatos dos diversos camponeses e a partir de nossas observações de campo, é muito comum entre a maioria dos proprietários de terras.

Em Minas Novas, a ArcelorMittal compra o carvão produzido pelos próprios camponeses. Já no caso de Campo Azul, o carvão é vendido diretamente aos caminhoneiros que o entregam na cidade de Sete Lagoas - MG, "alimentando" as principais indústrias "consumidoras" dos Cerrados de Minas Gerais. De mata nativa a eucalipto, os Cerrados mineiros estão sendo transformados em cinzas e, junto com eles, seus recursos, suas gentes e suas culturas.

O carvoejamento não é apenas uma atividade lucrativa, pois, para muitos camponeses, torna-se uma fonte alternativa de renda e sobrevivência no campo. Considerando o preço do metro cúbico de carvão (seis sacos conforme a FIG. 3) pago em julho de 2010 no município de Campo Azul, variando entre $R \$ 60,00$ e $R \$ 70,00$, podemos verificar que, para quem possui propriedades maiores, o carvão se torna uma atividade altamente lucrativa, no entanto ela não o é para a maioria das famílias camponesas. A observação das condições de vida das famílias camponesas entrevistadas nas diversas comunidades rurais de Campo Azul não nos permite caracterizar o carvoejamento como lucrativo, porém indica ser ele mais uma entre as várias formas de estratégias de reprodução social do campesinato, como é o caso do extrativismo do pequi ou do artesanato de barro em Minas Novas.

\footnotetext{
Que as águas voltem a minar nas minas (dos) gerais: os cerrados pedem socorro! 
Figura 3 - Carvoejamento oriundo de mata nativa em Campo Azul.

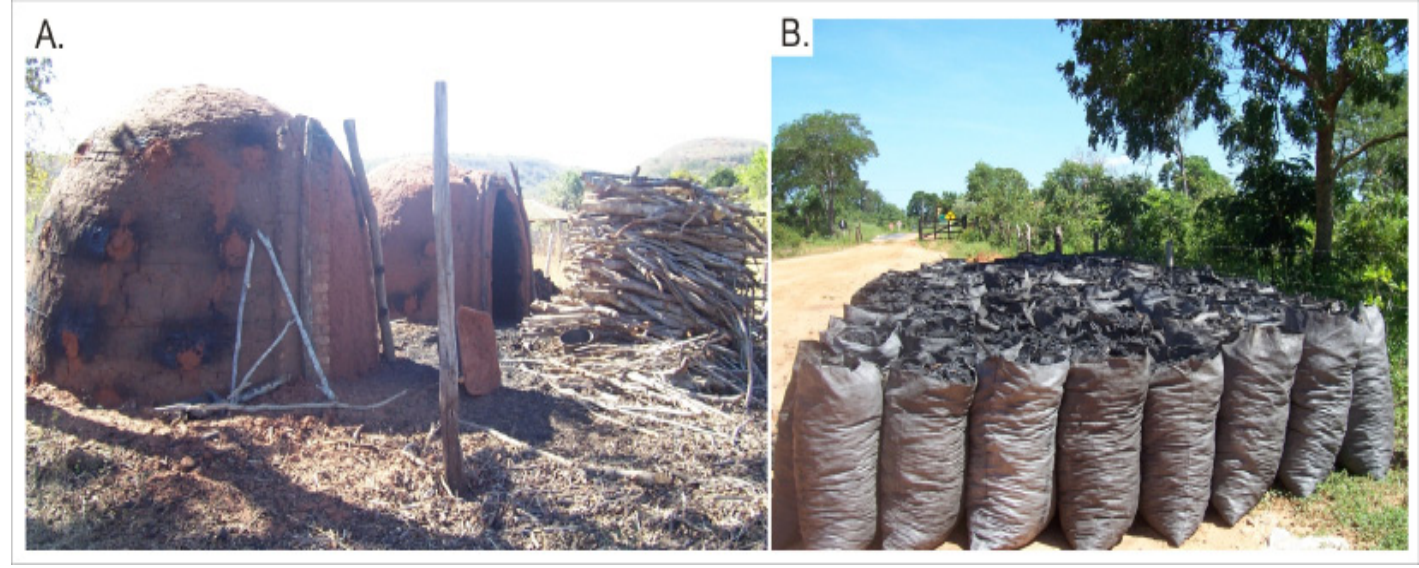

Fonte: SILVA, M. N. S.; Pesquisa de campo, janeiro e julho de 2010.

Realizamos entrevistas com os camponeses da comunidade rural Cabeceiras do Mangaí, em Japonvar, os quais também revelaram a existência do carvoejamento ilegal de mata nativa dos Cerrados. Todavia, com a expansão, organização e divulgação do município através do extrativismo do pequi, praticamente se extinguiu tal atividade predatória. Nesse sentido, Japonvar está um passo à frente em relação à promoção de ações de maior conservação dos recursos naturais quando comparado a Campo Azul, ambos no Norte de Minas Gerais.

Observando a FIG. 3, toda a problemática discutida anteriormente e, também, já pensando nas reflexões que se seguem, concordamos com Porto-Gonçalves (2000, p. 30-31) quando ele começa a analisar as consequências da "modernização" no Norte de Minas e, por nosso acréscimo, no Vale do Jequitinhonha, o qual compartilha das mesmas angústias:

Com o carvão, os eucaliptos e os projetos de irrigação, as águas já não minam nas minas do Norte de Minas. Os brejos começam a secar e, com isso, a cultura do feijão, do milho, da cana, do arroz, e outras do fundo dos vales, já não permitem fazer valer aquelas velhas matrizes de racionalidade, que ensejaram aquele regime alimentar rico e variado a que nos aludimos (grifos do autor).

Assim sendo, os cerrados do Norte de Minas e do Vale do Jequitinhonha compartilham das mesmas angústias daqueles do Brasil Central. Nestes cerrados, a monocultura de grãos, a criação extensiva e o agro/hidronegócio, termo usado por Mesquita (2009), são as principais atividades que eliminaram a biodiversidade, decretaram a morte das veredas e a eliminação e contaminação das águas. De forma semelhante, no Norte de Minas e Vale do Jequitinhonha, a monocultura de reflorestamento e o carvoejamento vão consumindo os cerrados e suas águas. Assim, os cerrados desaparecem junto com seus sabores, seus saberes, seus animais e suas gentes.

\section{Os caminhos dos cerrados... Para não concluir}

A perda da biodiversidade e a redução drástica dos recursos hídricos nas localidades estudadas são alguns exemplos do grito de socorro que nossos cerrados proferem. Altair Sales Barbosa (2004, p. 18) compara a situação dos Cerrados hoje com um fenômeno conhecido em Neurologia como Dor Fantasma, no qual as pessoas que perderam uma extremidade ou parte dela sentem dores às vezes muito intensas provenientes do membro que já não possuem mais. Para o autor, as discussões sobre o Cerrado se assemelham a essa situação, "porque estamos sentindo as dores da perda de um ambiente que não existe mais na plenitude de sua biodiversidade".

Geografia Ensino \& Pesquisa, v. 16, n.3 p. 93-106 set./dez. 2012

Silva, M. N. S. 
Assim sendo, o futuro dos cerrados e de suas populações hoje está condicionado à recuperação de seus diversos ambientes. Os problemas ambientais e sociais não se resolverão apenas com medidas paliativas, a exemplo de barraginhas, caixas de captação de água de chuva e bacias de contenção de enxurradas. Sem querermos desconsiderar a importância dessas medidas já utilizadas em várias áreas, os cerrados e sua gente precisam de intervenções mais concretas, cujo foco seja a conservação da diversidade biológica já existente e a recuperação das áreas degradadas, para que, com isso, as águas voltem a minar nas minas dos gerais.

Também é importante refletirmos sobre nosso papel ao chamarmos a atenção para os problemas supracitados ocorridos nos Cerrados de Minas Gerais. Indiscutivelmente, essas atividades, seja a monocultura do eucalipto ou o carvão de mata nativa, são extremamente degradadoras dos recursos naturais, entretanto, não é coerente afirmarmos apenas acerca da necessidade de fiscalização ambiental nessas áreas. Devemos considerar e propor ações que conduzam a um maior envolvimento e promoção de atividades produtivas, considerando o desenvolvimento social, econômico e ambiental, e nele as comunidades, os governos e outras instituições precisam estar integradas e alinhadas a uma única proposta.

A nosso ver, os camponeses entrevistados demonstraram estar conscientes quanto aos problemas ambientais gerados pelo carvoejamento, assim como possuem entendimento suficiente para perceber as consequências socioambientais dos empreendimentos capitalistas no seu território, por exemplo a monocultura do eucalipto. Não se resolve a problemática situação propondo a eliminação do carvoejamento entre os camponeses, mas reconsiderando e colocando o importante papel do camponês na conservação dos recursos naturais.

A experiência pioneira de Japonvar com o extrativismo do pequi, embora com alguns problemas, é um exemplo parcialmente bem-sucedido de caminho a ser trilhado, pois as comunidades abandonaram a renda obtida com o carvão para investir no pequi. Tal exemplo é importante porque cada vez mais é trabalhado o despertar ecológico entre os camponeses. Quanto mais o camponês constatar melhorias no seu dia a dia, a partir dos investimentos na conservação do meio ambiente, maior serão as iniciativas tomadas por ele. Diríamos que é o "bom senso" camponês.

Qualquer projeto a ser implantado em territórios rurais dos Cerrados do Norte de Minas e do Vale do Jequitinhonha, com vistas a eliminar atividades altamente impactantes aos recursos naturais, deve ter o propósito de mostrar aos sujeitos que eles terão muito mais benefícios a curto, médio e longo prazos se os Cerrados estiverem de pé.

\section{Referências}

AB'SÁBER, Aziz Nacib. Os domínios de natureza no Brasil: potencialidades paisagísticas. São Paulo: Ateliê Editorial, 2003. 159 p.

AGOSTINHO de JESUS, Geraldo. Agricultura camponesa/familiar e ação do Estado (PRONAF) no Vale do Jequitinhonha-MG: o caso de Minas Novas. 2007. 200 f. Dissertação (Mestrado em Geografia) - Instituto de Geociências, Universidade Federal de Minas Gerais, Belo Horizonte, 2007.

Geografia Ensino \& Pesquisa, v. 16, n. 3 p. 93 -106 set./dez. 2012

Que as águas voltem a minar nas minas (dos) gerais: os cerrados pedem socorro!
ALMEIDA, Maria Geralda de. A captura do cerrado e a precarização de territórios: um olhar sobre sujeitos excluídos. In. ALMEIDA, M. G. de. (Org.). Tantos cerrados: múltiplas abordagens sobre a biodiversidade e singularidade cultural. Goiânia: Ed. Vieira, 2005. p. 321-347.

ALMEIDA Jr., José Maria G. de. Uma proposta de ecologia humana para o cerrado. In: NOVAES PINTO, Maria (Org.). Cerrado: caracterização, ocupação e perspectivas. 2. ed. rev. e ampl. Brasília: Editora da Universidade de Brasília, 1994. p. 569-583. 
BRITO, Isabel Cristina Barbosa de. Comunidade, território e complexo florestal industrial: o caso de Vereda Funda - Norte de Minas Gerais. 2006. 157 f. Dissertação (Mestrado em Desenvolvimento Social) - Programa de Pós-graduação em Desenvolvimento Social, Universidade Estadual de Montes Claros, Montes Claros, 2006.

GUERRERO, Patrícia. Vale do Jequitinhonha: a região e seus contrastes. Revista Discente Expressões Geográficas, Florianópolis, n. 5, ano V, p. 81-100, maio 2009.

MAZZETTO SILVA, Carlos Eduardo. O Cerrado em disputa: apropriação global e resistências locais. Brasília: Confea, 2009. 264 p. (Pensar o Brasil - Construir o Futuro da Nação).

MESQUITA, Helena Angélica de. Onde estão as flores, as cores, os odores, os saberes e os sabores do cerrado brasileiro: 0 agro/hidronegócio comeu!. Terra Livre, São Paulo, ano 25, v. 2, n. 33, p. 17-30, jul./dez. 2009.

OLIVEIRA, Ariovaldo Umbelino de. Agricultura brasileira: transformações recentes. In: ROSS, J. L. S. (Org.). Geografia do Brasil. 5. ed. rev. e ampl., 1. reimpr. São Paulo: EDUSP, 2008. p. 465-534. (Didática; 3).

PORTO-GONÇALVES, C. W. As Minas e os Gerais - breve ensaio sobre desenvolvimento e sustentabilidade a partir da Geografia do Norte de Minas. In: LUZ, Cláudia; DAYRELL, Carlos (Org.). Cerrado e desenvolvimento: tradição e atualidade. Montes Claros: Ed. Unimontes, 2000. p. $19-45$

RIBEIRO, Ricardo Ferreira. História ecológica do sertão mineiro e a formação do patrimônio cultural sertanejo. In: LUZ, Cláudia; DAYRELL, Carlos (Org.). Cerrado e desenvolvimento: tradição e atualidade. Montes Claros: Ed. Unimontes, 2000. p. 47-106.

Sertão, lugar desertado - o Cerrado na cultura de Minas Gerais. Belo Horizonte: Autêntica, 2006, 376 p. v. 2.

RODRIGUES, Luciene. Formação econômica do Norte de Minas e o período recente. In: OLIVEIRA, M. F. M. de.; RODRIGUES, Luciene. (Org.). Formação social e econômica do Norte de Minas. Montes Claros: Ed. Unimontes, 2000

\section{Correspondência:}

\section{Marcos Nicolau Santos da Silva -}

E-mail: marcos.nicolau@yahoo.com.br

Recebido em 04 de abril de 2012.

Revisado pelo autor em 06 de dezembro de 2012.

Aceito para publicação em 06 de dezembro de 2012.

Geografia Ensino \& Pesquisa, v. 16, n.3 p. 93-106 set./dez. 2012 